\title{
Scanning and Georeferencing Historical USGS Quadrangles
}

\author{
"A government cannot do any scientific work of more value to the people at large \\ than by causing the construction of proper topographic maps of the country." \\ — John Wesley Powell to Congress, December 5, 1888
}

The U.S. Geological Survey (USGS) National Geospatial Program is scanning published USGS 1:250,000-scale and larger topographic maps printed between 1884, the inception of the topographic mapping program, and 2006. The goal of this project, which began publishing the Historical Topographic Map Collection (HTMC) in 2011, is to provide access to a digital repository of USGS topographic maps that is available to the public at no cost. For more than 125 years, USGS topographic maps have accurately portrayed the complex geography of the Nation. The USGS is the Nation's largest producer of traditional topographic maps, and, prior to 2006, USGS topographic maps were created using traditional cartographic methods and printed using a lithographic process. The next generation of topographic maps (US Topo) is being released by the USGS in digital form, and newer technologies make it possible to also deliver historical maps in the same electronic format that is more publicly accessible.

Topographic maps remain an indispensable tool for scientific and historical research, land-resource change management, recreation, and more. Historical maps are often useful to scientists, historians, environmentalists, genealogists, and others when researching a particular geographic location or area, as they represent the contemporary geographic information at the time of publication. A series of maps of the same area published over a period of time can show how some areas looked as early as 1884 , before current development, and provide a detailed view of changes over time.

Historical maps are stored in a limited number of collections and are not readily available to the public, so the USGS National Geospatial Program is converting these historical printed topographic quadrangles to an electronic format (GeoTIFF and TerraGo GeoPDF ${ }^{\circledR}$ ). This serves the dual purpose of creating a master catalog and digital archive copies of the irreplaceable collection of topographic maps in the USGS Map Library (Reston, Va.), as well as making the maps publicly available for viewing and downloading from several websites.

\section{Historical Topographic Map Benefits}

Building a comprehensive historical collection of topographic maps requires accurate cataloging and metadata creation (complete machine-readable information about each map) to accompany highresolution, georeferenced digital files of the lithographic maps. Georeferencing in the digital file allows basic map analysis to be done, such as pointing and clicking on the map to determine distance, area calculation, coordinate points, and other information. Each map image is scanned "as is" and captures the current content and condition of each one. The collection provides access to maps that are either no longer available for distribution in print or are being replaced by the next generation of US Topo maps.

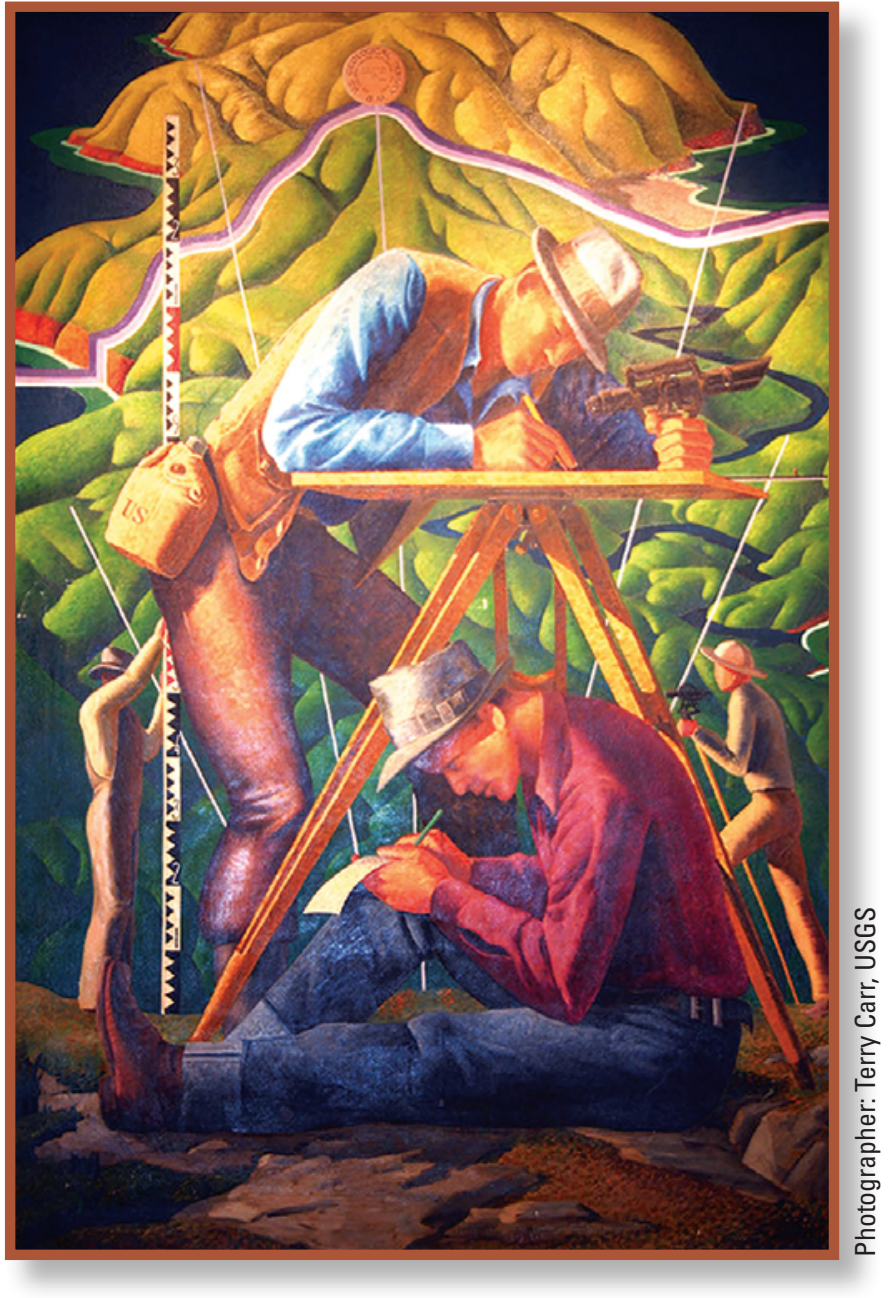

Cartographers in the field This Depression-era oil painting, created by Hal Shelton in 1940, depicts mapping techniques used in the early days of cartography, including an alidade and stadia rod for determining distances and elevations and a plane table for sketching contour lines.

Georeferencing of the map files - that is, tying them to a known earth coordinate system - enables them to be imported into a geographic information system (GIS) so that they can be overlain with other geospatial (map) data from other sources, such as from The National Map (TNM). The potential for research that analyzes change over time is becoming increasingly recognized by the 
geospatial community, and this project provides published lithographic USGS maps in georeferenced digital formats.

The scanned historical maps are available for general reference and viewing in a compressed portable document format (PDF) with geospatial extensions $\left(\mathrm{GeoPDF}^{\circledR}\right.$, by TerraGo Technologies). These files can be viewed and printed as PDF documents with a wide range of software. Using the geospatial extension requires Adobe Acrobat Reader ${ }^{\mathrm{B}}$ with the no-cost TerraGo Toolbar ${ }^{\circledR}$ for Microsoft Windows ${ }^{\circledR}$. The HTMC products are also delivered as GeoTIFF images with embedded metadata.

Download links and a user guide are available on the HTMC website. Paper copies of the historical maps can be purchased from the USGS Store. GeoTIFF and GeoPDF files will be added to the collection as they become available.

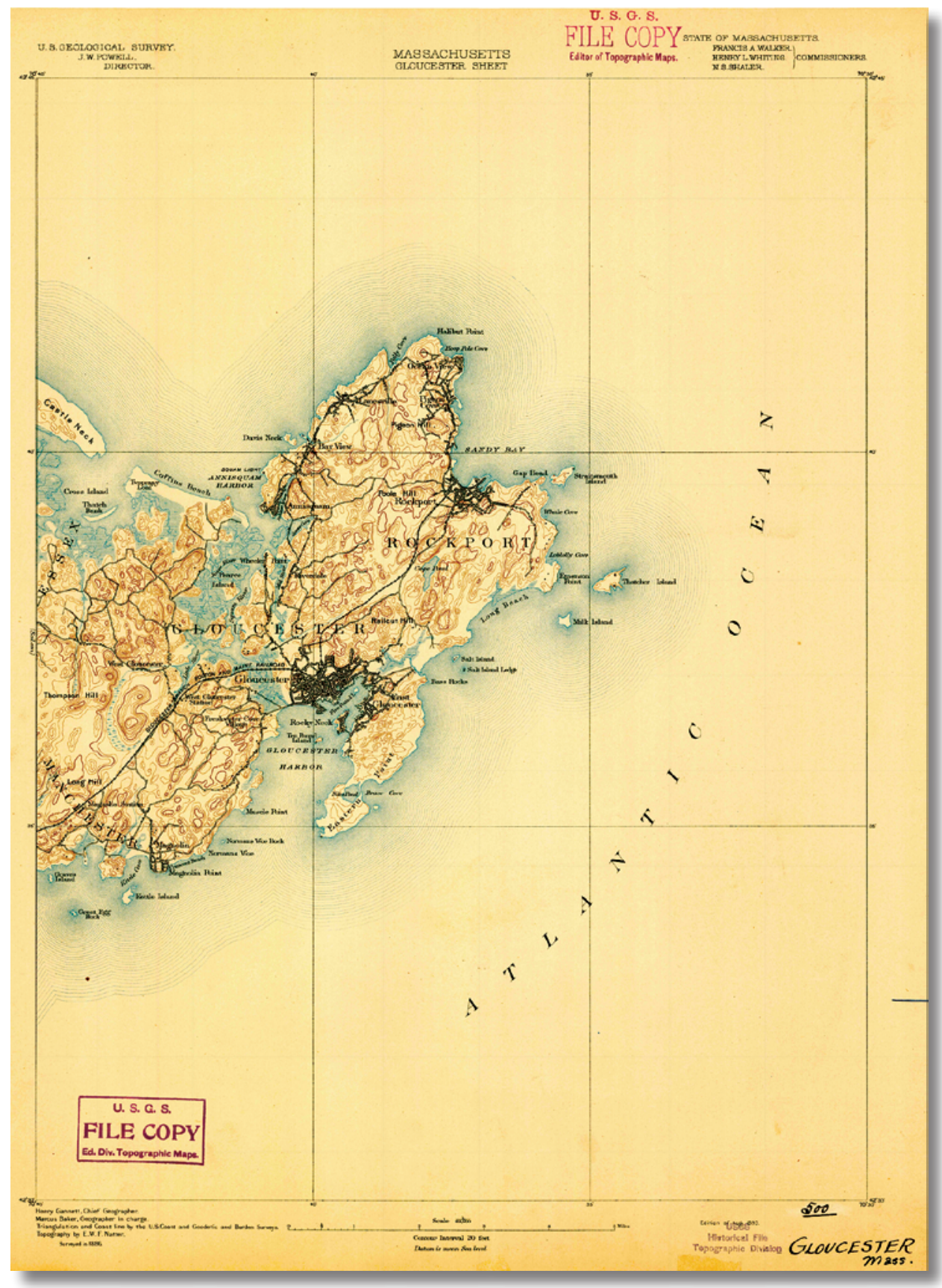

Massachusetts map from 1893 The first State to participate in the Cooperative Topographic Mapping Program.

\section{The USGS National Geospatial} Program

- Provides publicly accessible, downloadable, and viewable files for approximately 200,000 scanned maps, complete with metadata that is compliant with the Federal Geographic Data Committee.

- Provides historical paper maps in electronic form to complement the next generation of electronic topographic maps (US Topo).

- Maintains a catalog and metadata for all historical topographic maps that have been scanned and published in electronic form by the USGS.

- Develops and publishes specifications for scanning maps.

- Develops methods to efficiently create accurate, high-resolution, scanned georeferenced images.

- Archives published files with the National Archives and Records Administration and the Library of Congress.

\section{For More Information}

For information regarding the Historical Topographic Map Collection, go to https://nationalmap.gov/ historical.

To view and download information about The National Map, go to https://nationalmap.gov. To contact the USGS about The National Map, go to https://answers.usgs.gov or email nationalmap@usgs.gov. HTMC:

Download (free) maps from the

- topoView: https://ngmdb.usgs. gov/maps/Topoview/

- The National Map Downloader: https://viewer.nationalmap.gov/ basic/

- Text query application: https:// geonames.usgs.gov/pls/topomaps/

- Map Locator and Download application at USGS Store: https://store.usgs.gov/ 